\title{
PRIMERO DE MAYO, PRENSA Y DOMINACIÓN POLÍTICA EN COSTA RICA (1956-1980) ${ }^{1}$
}

\section{MAY FIRST, PRESS AND POLITICAL DOMINATION IN COSTA RICA (1956-1980)}

\section{Chester Urbina Gaitán*}

\section{RESUMEN}

El análisis de los discursos emitidos por la prensa nacional acerca de la celebración del primero de mayo después de finalizada la Guerra Civil de 1948, permite la comprensión del papel de los medios de comunicación en Costa Rica como agentes de socialización política. A un nivel general, manifestaron una posición moral-conservadora que invisibilizó la explotación del trabajador nacional, un furibundo anticomunismo y las condiciones económicas adversas que enfrentaban los campesinos.

PALABRAS CLAVE: COSTA RICA * TRABAJADORES * COMUNISMO * IGLESIA * CATOLICISMO * PRENSA

\section{ABSTRACT}

The analysis of the speeches emitted by the national press about the celebration of May Day after the end of the Civil War of 1948, allows understanding of the role of the media in Costa Rica as agents of political socialization. On a general level, they manifested a moralconservative position that made the exploitation of the national worker invisible, a furious anti-communism and the adverse economic conditions faced by the peasants.

KEYWORDS: COSTA RICA * WORKERS * COMMUNISM * CHURCH * CATHOLICISM * PRESS

$1 \quad$ El autor agradece los comentarios a una versión preliminar del texto realizada por el Dr. David Díaz Arias.

* Escuela de Estudios Generales de la Universidad de Costa Rica y Escuela de Ciencias Sociales y Humanidades de la Universidad Estatal a Distancia (UNED), Costa Rica.

chesterurbina@yahoo.com 


\section{INTRODUCCIÓN}

Después de terminada la Guerra Civil de 1948, el Estado asume una postura anticomunista al proscribir al partido comunista que dirigía al movimiento obrero nacional. Empero, aunque la izquierda mantuvo su dominio entre los trabajadores bananeros, las organizaciones y la cultura de los operarios urbanos tendieron a desaparecer (Molina y Palmer, 2017). El disentimiento de los trabajadores citadinos $y$ bananeros sobresalió entre 1948 y 1954. Los pequeños y medianos caficultores se expresaron en apoyo de regular mejor su relación con la burguesía cafetalera en 1961. También a principios de los años sesenta, los campesinos pobres, organizados temporalmente en ligas y comités de orientación izquierdista, comenzaron a manifestar su malestar públicamente (Molina y Palmer, 2017).

Después de 1950, el movimiento trabajador costarricense quedo dividido; por un lado, los simpatizantes del llamado "régimen de los ocho años", integrado por una buena parte de los obreros urbanos, quienes fueron influenciados por la locuacidad reformista; por otro lado, los partidarios de José Figueres Ferrer y su grupo político, agrupados en el Partido Liberación Nacional desde 1951. Para Manuel Rojas (1978), a la clase obrera y al campesinado les llevaría años el poder escapar a esa dicotomía política muy explotada por los políticos burgueses para su beneficio.

El Partido Liberación Nacional, a pesar de llamarse social-demócrata, no tuvo una base obrera organizada ni estimuló su desarrollo. Por medio de una política de concesiones que no alteraba el modo de producción capitalista, Liberación Nacional logró articular una base de apoyo entre la burguesía urbana, el campesinado y una parte del proletariado; pero sistemáticamente su organización ha rehuido. Asimismo, la intromisión de la Organización Regional Interamericana de Trabajadores (ORIT) $y$ de la Federación Estadounidense del Trabajo y Congreso de Organizaciones Industriales (del inglés American Federation of Labor and Congress of Industrial Organizations, comúnmente denominada AFL-CIO) promovió la burocratización de la Confederación Costarricense de Trabajadores Rerum Novarum (CCTRN), así como una política de contención de los conflictos obrero-patronales, es decir, de un sindicalismo acoplado al sistema (Rojas, 1978).

Con la llegada de la década de los setenta $y$, principalmente, de la crisis mundial a partir de 1975, las condiciones económicas y sociales de las clases subalternas se vieron afectadas seriamente. Las expectativas que el reformismo se había encargado de crear, dejaron de cumplirse debido a que la expansión de los servicios fue insuficiente para cubrir las necesidades de una población en crecimiento. El descontento permitió el surgimiento de protestas, sobre todo a nivel comunal, lo cual permitió que sectores importantes del proletariado y del campesinado pobre alcanzaran niveles mayores de conciencia sobre sus intereses de clase y las formas de organización adecuadas para su lucha (Rojas, 1978; Alvarenga, 2005). Esta movilización dio origen a una férrea represión estatal, principalmente contra organizaciones que las cámaras patronales consideraban que atentaban contra sus intereses.

En este escenario de sometimiento político, la celebración del primero de mayo se constituyó en el principal canal de impugnación político-cultural de los sectores trabajadores de Costa Rica, la cual comenzó a ser encauzada, controlada y dirigida tanto por el Estado como por la Iglesia católica. Debe señalarse que a partir de la segunda mitad del siglo xx, la jerarquía de la iglesia católica conformó una relación simbiótica con el Estado, esto en cuanto ha sido una asociación en que las dos partes se han beneficiado (Maroto, 2013; Opazo, 1987). Según Miguel Picado (1990), esta simbiosis político-cultural permitió que el Estado orientara el accionar de la iglesia, la cual mantuvo "una dependencia con el proyecto desarrollista impulsado por el Partido Liberación Nacional" (p. 43).

Fundamentado en todo lo anterior, es que el presente artículo tiene como objetivo analizar los discursos emitidos por la prensa nacional acerca de la celebración del primero de mayo después de finalizada la Guerra Civil de 1948. Esto con el fin de comprender el papel de los medios de comunicación en Costa Rica 
como agentes de socialización política. La socialización política se produce a lo largo de la existencia de los individuos y por medio de los diferentes tipos de productos culturales de los medios (Montero, 1989). Según Chomsky y Herman (2000), los medios "actúan como sistemas de transmisión de mensajes y símbolos para el ciudadano promedio. Su función es la de divertir, entretener e informar, así como inculcar a los individuos los valores, creencias y códigos de comportamiento que les harán integrarse a las estructuras institucionales de la sociedad" (p.21). Pese a lo anterior, a través de los medios también se emiten discursos impugnadores de rechazo a la visión política hegemónica y al interés de que el individuo se adapte al orden dominante. Se entiende por hegemonía:

... un fenómeno social que explica la dominación, mantenimiento y reproducción del poder que ejerce un grupo específico sobre otros, imponiendo ya se por medio de medios coercitivos o no, sus poderes económicos, la represión, y sobre todo los valores, creencias e ideologías que ayudan a configurar y sostener el sistema establecido (Barrientos, 2019, p.102).

El estudio de esta celebraciónse realizó con base en la revisión de los periódicos el Eco Católico entre 1956 y 1980 y La República entre 1963-1975. Las fechas de inicio de consulta de los medios escritos antes referidos se justifica de la siguiente manera: fue a partir de 1956 que la Iglesia Católica dio a conocer su posición con respecto a la celebración del primero de mayo en el país. Por otra parte, es a partir de 1963 que La República comunica su posición ante la festividad en estudio.

La posición política de la Iglesia Católica expuesta en el Eco Católico se confrontará con los editoriales emitidos por La República, principal periódico de la época, "para comprender su grado de alineación a la cruzada mundial anticomunista que Estados Unidos encabezaba durante la Guerra Fría, donde se presentaba al comunismo como sinónimo de violencia, revolución, ateísmo, radicalismo y dictadura (del proletariado o de una persona) que se quiso propagar en el país como un concepto que representaba lo inverso a paz, democracia, cristianismo, estabilidad, libertad e igualdad" (Barrientos, 2019, p.98). El análisis discursivo de los periódicos citados concluye en 1980, ya que en esa fecha es que la celebración en estudio comienza a declinar (Oliva, 1985).

\section{ANTICOMUNISMO, CONSERVADURISMO MORAL Y DOMINACIÓN POLÍTICA: LOS DISCURSOS PERIODÍSTICOS EN TORNO A LA CELEBRACIÓN DEL PRIMER DE MAYO EN COSTA RICA}

(1956-1980)

La Guerra Fría en Centroamérica denotó una cruzada encabezada por los Estados Unidos, la CIA (Central de Inteligencia Americana) y los Estados nacionales burgueses, que podían ser dictaduras militares neofascista o regímenes democráticos burgueses. Tales estructuras políticas arremetieron contra los comunistas y los simpatizantes de izquierda, es decir, contra el supuesto enemigo común de todo buen demócrata cristiano y pacifista. La actuación violenta de los Estados centroamericanos se justificaba debido a que el fin último era desaparecer el comunismo entre 1945 y 1991, formal e informalmente. La estrategia que se utilizó giró entre la difamación, la mentira, la exageración, el adoctrinamiento, la ideologización planificada, la violencia de Estado, la guerra terrorista y la represión a los partidos, sindicatos y trabajadores que fueran "sospechosos" (Barrientos, 2019).

Según Manuel Gamboa (2013), tal y como sucedía en toda América Latina, durante los años de la Guerra Fría y con la Revolución Cubana desarrollándose, en Costa Rica, la elite política le tuvo miedo a los comunistas, a pesar de que estos eran pocos a nivel numérico. De esta manera, en las campañas electorales después de 1948, se va a reflejar una necesidad por demostrar un comunismo donde en realidad muchas veces no existía. Algunos políticos expresaban en los principales periódicos el "derecho" del conocimiento sobre las ideas originadas del marxismo, $y$ lo hacían por medio de discursos estereotipados donde incluso predominaba la perspectiva religiosa (Gamboa, 2013). 
Para el 22 de abril de 1956, el Eco Católico dio a conocer su editorial denominado: "El día del trabajo", donde señala que existían personas en el país que se presentaban como abanderados y apóstoles de los trabajadores, lo cual consideraban como el único y supremo valor de la vida, desconociendo y luchando contra otros valores como los sobrenaturales. Según este periódico religioso, el trabajo era fundamento o título justificativo de derechos, que se podían compendiar de la siguiente manera: "Respeto a la persona del trabajador como hombre, como padre de familia, como ciudadano y como cristiano. El trabajo del hombre debe ser no su servidumbre, sino su libertad, no una condena, sino un privilegio por el que se reafirma su parentesco con Dios" (El día del trabajo, domingo 22 de abril de 1956, p. 353). En este texto, se evidencia una visión política que invisibiliza la existencia de una dominación de clase y de la explotación del trabajador nacional, la cual se deriva de la vinculación política existente entre el Estado y la Iglesia católica. La atención política de la jerarquía de la iglesia católica se centró en la clase media, debido a que fue una estrategia que le permitía neutralizar la lucha de clases, pero principalmente fue un medio óptimo para el mantenimiento de la moral familiar que ayuda a conservar el statu quo (Picado, 1990).

Asimismo, recuerda que el primero de mayo se creó para festejar la rendición de William Walker en 1857. Este mensaje lo dirigía a los hombres que se manifestaban en esta fecha con banderas, cartelones y estandartes pidiendo paz y libertad, lo cual se realizaba por el sacrificio de los hombres que participaron en las gestas heroicas del 20 de marzo y el 11 de abril de 1856 (El día del trabajo, domingo 22 de abril de 1956). Con esta posición de civismo, se pretende deslegitimar la celebración del primero de mayo como día del trabajador y volver a su festejo original (Marín y Torres, 2015; Urbina, 2015).

Un año después se mantiene la misma posición cuando "Benedictino" publicó: "Ennoblecer el trabajo", en el cual se hace un llamado para que no se trabajara como el esclavo que trabaja por temor al látigo, ni como aquellos que trabajan tan solo por la paga. Se debe trabajar por un motivo superior, inspirados en alguna idea noble, sobre todo por amor a Dios. De esta manera: “...así nuestras obras dejan de ser cosa material para convertirse en oro del Cielo" (Benedictino, domingo 28 de abril de 1957, p. 330).

En 1961, en el editorial "Concentración católica del trabajo", se ataca la celebración del primero de mayo que organizaban los lideres sindicalistas comunistas.

Entonces, cuando la Iglesia habla de justicia social, no puede dejar de lado la caridad que es más perfecta. En eso la Iglesia se diferencia del comunismo que suplanta la caridad por el odio y la lucha de clases y llega al resultado del crimen para implantar lo que ella llama su "justicia social", materialista y condenada a producir mayores males en la humanidad. En ello también se diferencia la Iglesia del socialismo que sustituye la caridad por la cooperación y a Dios por el Estado (Concentración católica del trabajo, domingo 30 de abril de 1961, p. 359).

A lo anterior, se agrega que un trabajador consciente $y$ honrado consigo mismo, no podía evitar llegar a la conclusión de que ninguna institución y ninguna filosofía le podían asegurar la paz social como se la da el catolicismo (Concentración católica del trabajo, domingo 30 de abril de 1961). Con el fin de contrarrestar la influencia comunista entre los trabajadores, la Iglesia ideó realizar una celebración del primero de mayo paralela a la organizada por los líderes trabajadores, la cual comenzó a realizarse en la plazoleta de la Iglesia de La Soledad a partir de 1961. A esta actividad asistieron el Nuncio Apostólico, el Arzobispo Metropolitano, los obispos de Alajuela y de Limón, y el Ministro de Trabajo. El primero en tomar la palabra fue el Arzobispo Monseñor Carlos Humberto Rodríguez Quirós, quien aclaró cuál era el motivo de la concentración:

$\mathrm{Si}$, obreros costarricenses y empresarios de nuestra católica Costa Rica, hemos concurrido hoy a este llamamiento de la Iglesia, para tomar posiciones netamente 
definidas y absolutamente irrevocables contra el comunismo ateo y el socialismo materialista, que se está introduciendo en nuestra América con la violencia que le es propia y con el consiguiente desprecio y ofensa de las sagradas libertades humanas que son el precioso patrimonio de nuestra civilización cristiana (Guerra, domingo 7 de mayo de 1961, pp. 374-375).

Los falsos señalamientos hechos por Monseñor Rodríguez sobre la promoción de la violencia a un nivel continental por parte de los sectores de izquierda, demuestran un interés de ocultamiento de la política internacional de los Estados Unidos marcada por los "cuartelazos preventivos" y una clara política intervencionista de los Estados Unidos, como sucedió en Guatemala en 1954 y en la República Dominicana en 1965. Para Muñoz (2008-2009), a nivel interno, la existencia de organizaciones particulares con tendencias militares y sus evidentes nexos con determinados partidos políticos, el no abandono de la violencia como alternativa política, la radicalización del discurso y la propaganda anticomunista desde principios de los años 60 y la militarización de la Guardia Civil más su preparación en tareas de contrainsurgencia, son factores que en su conjunto, no solo polarizaron a la sociedad costarricense, sino que también significaron una seria amenaza contra el sistema democrático, colocando sobre el tapete las soluciones de carácter autoritario.

El obrero don Alcides Vargas en un tono moral-conservador indicó que no hay demanda de justicia que no se pueda plantear desde la anchurosa plataforma del cristianismo. Asimismo, agregó: "Estamos aquí con un mensaje de solidaridad cristiana para todos nuestros compañeros de trabajo con una consigna cargada de esperanza. "Trabajadores de todo el mundo uníos, sí, pero uníos en Cristo por la Justicia y la Paz"." (Guerra, domingo 7 de mayo de 1961, p. 378).

Posteriormente, tomó la palabra don J. Joaquín Chaves B., quién manifestó una posición reaccionaria en la misma línea política de las dos anteriores:
Estamos aquí, los trabajadores ticos, los trabajadores costarricenses en este primero de mayo de 1961, lanzando una modesta pero sublime proclama al mundo, para manifestar resueltamente que, en este pequeño trozo de tierra americana, llamada Costa Rica, jamás se izará la bandera de la hoz y el martillo (Guerra, domingo 7 de mayo de 1961, p. 380).

Esto lo señalaba debido a que la bandera de la Unión de Repúblicas Socialistas Soviéticas era una bandera teñida de rojo debido a la sangre de millones de hermanos muertos en defensa de su ideal de libertad. Sobre el anticomunismo en Costa Rica, James Backer señala que el prejuicio sobre la relación entre cambios sociales y el anticomunismo se reforzó en la opinión pública durante la década de los años cuarenta. Un elemento característico del pensamiento colectivo costarricense es el de la mentalidad de clase media. Esta mentalidad de clase media produce desconfianza hacia los movimientos obreros (Backer, 1975).

Pasaran cuatro años para que el Eco $\mathrm{Ca}$ tólico vuelva a emitir una nota editorial relativa a la celebración del primero de mayo. En 1965, en el editorial "Los camaradas atacan", se denuncia que en la celebración de esa fecha el Partido Vanguardia Popular repartió una hoja poligrafiada en la que se decían mentiras sobre la Iglesia católica, aunque no se publicó. El periódico religioso se defendió exaltando la labor social de la iglesia en el país, al decir que esta institución fomentó la educación profesional y vocacional, también construyó casas para los pobres y creó "Caritas". A un nivel general, se afirma que donde se levantara un hospital, un centro de nutrición y de beneficencia estaba la mano de la iglesia y del sacerdote. Asimismo, se aclara que el Lic. Manuel Mora Valverde había protestado por los términos de la hoja volante (Los camaradas atacan, domingo 9 de mayo de 1965).

La iglesia católica durante los años de estudio tenía un potencial enorme para influir en la opinión pública con respecto al desarrollo socio-económico en general, $y$ en el sindicalismo. Disponía de las misas y otros actos religiosos, 
la prensa católica y los centros de enseñanza católicos. Con respecto a la clase obrera, la iglesia estableció tres organizaciones que trataban de mantener lazos con los trabajadores: las Hermandades del Trabajo, la Juventud Obrero-Católica y la Liga Espiritual Obrera. Mientras que los propósitos de la tercera organización son espirituales, las dos primeras forman a laicos activos en el proceso de desarrollo socio-económico.

En el caso de CARITAS, esta institución ha distribuido alimentos a familias pobres a cambio de su colaboración en varios proyectos de desarrollo local. También existían varias asociaciones de ahorro y crédito controladas o apoyadas por la iglesia. Asimismo, debe destacarse la participación individual de los sacerdotes en organizaciones públicas o privadas (Backer, 1975). Pese a la creación de estas instituciones, debe señalarse que la jerarquía eclesiástica, al tiempo que se distanciaba del compromiso social con el que se identificó en la década de 1940, adversaba la "opción por los pobres" promovida por el Concilio Vaticano II (1962-1965) y la Conferencia Episcopal de Medellín (1968) (Molina y Palmer, 2017).

La Iglesia católica no perdió su influencia en la sociedad costarricense después de la guerra civil de 1948, por el contrario, salió fortalecida. La Asamblea Constituyente de 1949 discutió tres aspectos importantes: la participación política del clero, la confesionalidad del Estado y la educación. En este proceso se les permitió a los sacerdotes ser electos como diputados, pero se imposibilitó su participación para los cargos de la Presidencia y Vicepresidencia de la República, Ministerios y Magistrados de la Corte Suprema de Justicia. La confesionalidad del Estado quedó consignada en el artículo 75 de la Constitución Política, adoptando el mismo texto de la Constitución de 1871. Además, se aseguró la participación e influencia de la iglesia en el diseño y supervisión de los programas de enseñanza (Maroto, 2013; Benavides, 2005; Campos, 2000).

En 1967, Claudio Gamboa, Secretario General de la Confederación de Obreros y Campesinos Cristianos Costarricenses, dio a conocer "Los trabajadores queremos un diálogo", en el cual critica la dependencia de los costarricenses hacia el Estado: "Los trabajadores costarricenses todo lo esperan de arriba. No han participado activamente en esa lucha por el bienestar económico y social. Por otra parte, destacaba que no se ha favorecido el sentido de responsabilidad de los trabajadores" (Los trabajadores queremos un diálogo, domingo 7 de mayo de 1967, p. 12). También decía que el primero de mayo debía de ser solo para celebrar el día del trabajo, pero en el país se seguía la tradición de celebrar la finalización de los períodos legislativos. En esta fecha, el Presidente de la República rendía su informe de labores, lo cual no les permitía a los funcionarios asistir a los actos de celebración del día antes referido y tener un diálogo con los trabajadores obreros.

La crítica de don Claudio hay que matizarla en el sentido de que el Estado se dedicó a canalizar legal y pacíficamente las necesidades y el conflicto social a través de la creación de entidades especializadas como el Instituto Costarricense de Electricidad (ICE), el Instituto Mixto de Ayuda Social (IMAS), Acuaductos y Alcantarrillados (AyA) y la Dirección Nacional de Desarrollo de la Comunidad (DINADECo). Para Molina y Palmer (2017), el propósito básico de esas entidades era desmovilizar las protestas; sin embargo, debían satisfacer, en algún grado, las demandas populares para cumplir ese objetivo eficazmente. Para 1972, Jorge Campos S. en su artículo "Los ticos en su salsa", critica la dependencia del costarricense hacia las políticas sociales estatales:

Pareciera que los obreros, ese inmenso mundo al que todos dicen que aman, que quieren defender, padece el mismo mal que otros sectores de nuestra sociedad que todo lo esperan del Estado. Para más de uno el Estado no es sino un papá grandote que debe solucionarle cuantos apuros se presenten en la vida (Campos, domingo 30 de abril de 1972, p. 4).

Entre los principales factores culturales que son adversos a la sindicalización en el país destacan el individualismo y el personalismo. El costarricense desconfía de las organizaciones en general $y$ por eso da su apoyo a individuos. En la mayoría de los movimientos 
sociales o políticos, el "jefe supremo" es mucho más importante que la organización en sí. Otros rasgos son el paternalismo y el tradicionalismo (Backer, 1975).

En el artículo anónimo denominado " $1^{\circ}$ de mayo con trabajadores sin representación", se señala que en el momento en que se encontraba la historia política de Costa Rica se revelaba una tendencia hacia la polarización de las fuerzas de poder, con la consiguiente desmitifación de los valores pequeño burgueses creados por los partidos tradicionales para perpetuarse en el poder. Esta polarización se percibía tanto en los grupos de extrema derecha como en los nacientes grupúsculos de izquierda (1 de mayo con trabajadores sin representación, domingo 30 de abril de 1972). En los dos textos anteriores se evidencia la existencia de discursos informales que rechazan el orden político-cultural establecido por el Estado a través del paternalismo y de los valores pequeños burgueses. Se entiende por discursos informales:

...todos aquellos que, sin ser aceptados oficialmente, reflejan las disensiones $y$ conflictos dentro de las instituciones. Se convierten en discursos públicos en función de los intereses de los diferentes grupos institucionales o personas que participan de esa situación conflictiva (Montero, 1989, p.94).

También se refiere a que la creación del Mercado Común Centroamericano y los repetidos intentos de unión política y cultural de los países centroamericanos habían conseguido orientar hacia la izquierda a muchos campesinos y obreros, sobre todo a los intelectuales centrados de la Universidad de Costa Rica. Asimismo, se resalta la pauperización acelerada de la pequeña y mediana burguesía. Sin embargo, el énfasis de la publicación era una crítica frontal a la institucionalidad y a la dominación cultural existente en el país.

Para el autor Jorge Campos: "Tres eran las instituciones que sustentaban la idiosincrasia nacional. La familia, el sistema educativo y la iglesia. Todas eran responsables de la alienación que experimentaba el costarricense, las cuales lo hacían vivir en un infantilismo que inhibía su creatividad y domesticaba su libertad, incapacitándolo para ser dueño de su destino. El hogar se resentía profundamente de la tradición machista, que traía como consecuencia una excesiva influencia materna, sobre todo en los varones, que creaba en ellos una pseudo personalidad edípica y los hacia buscar en las instituciones públicas, tanto estatales como religiosas, una prolongación del regazo materno. El sistema educativo era visto por la población más como una posibilidad de ascenso económico que como un medio de formación integral. Solo era un medio de asimilación al sistema social" (Campos, domingo 30 de abril de 1972, p. 11). Esta afirmación es corroborada por Iván Molina cuando refiere que es a partir de la década de 1950 que la inversión educativa pública creció de manera excepcional, en el marco de las políticas desarrollistas puestas en marcha en ese momento. Tales medidas, que en parte se debían a la preocupación por ampliar el mercado interno, propiciaron la movilidad social y se dirigieron a disminuir las desigualdades: entre 1961 y 1977, la proporción de hogares pobres disminuyó de 51\% a 25\% (Molina, 2018).

Pasaron siete años sin que el Eco Católico se refiriera a la celebración del primero de mayo, lo que indica la decadencia de dicha actividad. Esto se fundamenta en el sentido de que de los 809 sindicatos constituidos entre 1943 y 1970, 524 fueron cancelados y 50 estaban inactivos, $y$ se hallaban en proceso de cancelarse. Es decir, de los 809 sindicatos, solamente 235 estaban vigentes y activos en 1970 (Backer, 1975). En el editorial "Fue borroso el día del trabajo", en una forma reaccionaria se critica el hecho de que muchos cristianos estaban cayendo en el juego político que venía del sector ateo, sobre todo marxista o leninista. Si al trabajo se le quitaba su carácter sagrado, pasaba a ser un arma excelente para atizar el choque entre las clases empresariales y los obreros. Al referirse acerca de los reclamos hacia la reivindicación del trabajador, del alto costo de la vida y del aumento de los salarios, se señala:

Como si el dinero fuera la llave mágica que como varita de oro hiciera feliz al hombre. Como si el costo de la vida no 
fuera un producto directo de la mucha vagabundería que priva en Costa Rica en donde se quiere cada vez menos un trabajo y más dinero. Como si la reivindicación del trabajador se obtuviera pegando gritos en las calles y escribiendo desafíos en trapos que se llevan en desfiles (Fue borroso el día del trabajo, domingo 6 de mayo de 1979, p. 2).

Frente a la peroración interior se debe aclarar que los sectores trabajadores dieron duras luchas por defender sus derechos laborales $y$ poder vivir dignamente. La huelga por el aguinaldo de diciembre de 1959 y enero de 1960, concluyó un largo proceso de reorganización sindical de recuperación de los sindicatos ilegalizados o intervenidos por el figuerismo. En un duro proceso de varios años, los sindicatos logran superar la falsa división pro patronal de la Central de Trabajadores Rerum Novarum e implantan una unidad de acción anti patronal por la base. Desde 1952 hasta 1959 hay una serie de huelgas con las más variadas razones y reivindicaciones: deficiencias en los servicios de salud, vivienda, agua, higiene, transporte $y$ recreo; disminución en las remuneraciones y menoscabo del salario mínimo; cambios en los horarios y en las tareas establecidas en el contrato laboral; maltrato de jefes, capataces y mandadores; violaciones al derecho de organización y libertad sindical. Por otra parte, en los años setenta, para la clase trabajadora se generaliza la negociación de convenciones colectivas de trabajo, las cuales logran una mejora importante en las condiciones en las que los trabajadores ofrecían su fuerza de trabajo, no solo aumentando su salario real, sino también su salario social (Herrera, 2015).

En 1980, en el editorial del 4 de mayo de ese año llamado "El primero de mayo", se indica que el movimiento sindicalista en el país no era comunista, pero que a los líderes comunistas le interesaba mucho ser sus jefes, los líderes y los guías para convencer a los incautos trabajadores de la bondad de su ideología (El primero de mayo, domingo 4 de mayo de 1980). Este discurso es solo una opinión personal, no se ilustra con ningún caso en específico.
Con respecto a los editoriales publicados por La República en torno a la celebración del primero de mayo, se tiene que el miércoles 1 de mayo de 1963 se daba a conocer el "Manifiesto del 1 de mayo de oriT", en el cual se expresa una posición furibundamente anticomunista. Así, por ejemplo, se señala que la Organización Regional Interamericana de Trabajadores (ORIT) fue la fuerza decisiva que incitó a los gobiernos a promulgar una mejor Legislación del Trabajo, a perfeccionar la seguridad social, a estudiar e instituir la Reforma Agraria cuya urgencia era indiscutible, en fin, a luchar contra la miseria, la ignorancia y la insalubridad. También esta institución se proclama en adalid de la democracia en el continente:

La ORIT combate tanto a las dictaduras reaccionarias de derecha, que enriquecen más a los ricos fortaleciendo a las oligarquías...como a las dictaduras demagógicas de izquierda que empobrecen más a los pobres al hacer que descienda para los trabajadores su nivel de vida, como ocurre en Cuba comunista, donde una casta burocrática y militarizada explota sin freno alguno a los obreros privándolos de toda clase de derechos libertades (Manifiesto del $1^{\circ}$. de mayo de ORIT, miércoles 1 de mayo de 1963, p. 7).

La misma posición política se manifestó dos años después en el editorial "Día del trabajo" cuando se indica:

Muchas veces los trabajadores han sido expoliados, engañados y utilizados para fines logreros. Confundiendo al proletariado con un Partido llamado de "la clase trabajadora", se le ha tomado de instrumento paradójico de la doctrina extranjera que actualmente pretende imponerse por la fuerza en el mundo. Pero para sus conquistas, ha sido necesaria la exterminación, el asesinato en masa de millones de trabajadores (sábado 1 de mayo de 1965, p. 6).

Estos dos textos confirman lo señalado por Jorge Barrientos, en que los feroces ataques 
a una Cuba que ya era declarada comunista por el resto del mundo, se comprueba en los cada vez más agresivos discursos y argumentos contra el gobierno de este país, y en favor de una invasión para acabar con su gobierno (Barrientos, 2019, p.613).

El domingo 1 de mayo de 1966, el periódico La República en el editorial "1 de mayo" refería a que el país en los últimos cuatro años de gobierno había avanzado en cuanto a la expansión de los servicios públicos, el ingreso de divisas y la mejoría en varias de la balanza de pagos. Sin embargo, existían deficiencias con respecto a que el campo no producía lo suficiente ni a buen precio, no existían amplias facilidades para obtener vivienda salubre y educación totalmente gratuita, los campesinos no estaban en plena posesión de sus tierras, etc.

Sobre lo anterior, Herrera (2015) apunta que es hasta la década de los setenta, cuando la implantación de las convenciones colectivas en el país permitió el logro de conquistas: subsidios de alimentación, pago de medicinas no cubiertas por el seguro social, transporte gratuito, pluses por trabajos insalubres o peligrosos, pago de exámenes médicos, incentivos al salario base, extensión de las vacaciones y de las facilidades para disfrutarlas, aumento del valor de la hora extra trabajada, entre otras.

El lunes 1 de mayo de 1967, en la editorial "Primero de mayo", se indica que la mejor forma de celebración de esta fecha en Costa Rica era abrir consultorios jurídicos gratuitos para el acceso y beneficio del trabajador. Esto le permitiría al trabajador obtener justicia pronta y cumplida. También se le recordaba al lector que en un primero de mayo fue expulsado el filibustero William Walker, quien amenazaba la soberanía centroamericana y la libertad del país. Para finalizar este editorial, La República señala que hacía votos por un redoblado esfuerzo conjunto de las fuerzas del capital y el trabajo para salir airosos de las duras pruebas (Primero de mayo, lunes 1 de mayo de 1967). Ante esto debe señalarse que fueron las luchas sociales las que permitieron la obtención de conquistas como el aguinaldo y las convenciones colectivas, las cuales mejoraron las condiciones de vida de la población trabajadora, y no fue tanto por el interés del capital y de los empresarios nacionales.

En 1969, este diario critica que el primero de mayo fuera una fecha en la que se exalta solamente al obrero, como si el trabajo no fuera atributo también de otros sectores de la sociedad. Para este periódico, esta unilateralidad en la conmemoración de esta fecha ha servido para que algunos tracen una línea divisoria entre obreros $y$ patronos, entre ricos $y$ pobres, entre poseedores y desposeídos, alcanzando así uno de los objetivos de los conflictos sociales: la lucha de clases. Supuestamente, esta visión parcializada sirve para que sean los agitadores los que levanten la bandera de la reivindicación social. Era lamentable que esta celebración se haya reducido a manifestaciones exteriores, cuando no propagandísticas. En vez de esto, era mejor que el día del trabajador fuera precedido por fecundo período de preparación e instrucción, que es una de las mejores maneras de dignificar al trabajador $y$ de preservarlo de predicas extrañas, ante las cuales pueda sucumbir por falta de instrucción (El día del trabajo, jueves 1 de mayo de 1969). La evidencia empírica expuesta hasta aquí permite señalar que el acceso a la educación no conlleva automáticamente al mejoramiento de la calidad de vida de los trabajadores, por lo que el discurso anterior puede ser considerado retrógrado.

En 1973, en el artículo "Otro primero de mayo" se critica que para los primeros de mayo se indicaba que en el país todos eran trabajadores. Sin embargo, al momento de luchar en beneficio del trabajador, la definición cambia según los intereses de cada dirigente o agrupación. En el país, los únicos organizados eran los empleados públicos. El campesino, en cambio, no estaba organizado y era el gran ausente de estas celebraciones. También se aclara que los grupos de presión principales estaban integrados, por un lado, por los dirigentes políticos, los empresarios y los profesionales, por el otro, por los empleados públicos. Es decir, los grupos de presión más importantes y poderosos pertenecían a la clase media. Esta es la que ha recibido 
los beneficios del Estado $y$ ha sido tradicionalmente la mimada de los partidos políticos y de los gobiernos. Debido a esto es que los demás grupos de trabajadores no recibían los beneficios estatales y se encontraban en condiciones precarias (Otro primero de mayo, martes 1 de mayo de 1973).

Lo anterior evidencia que durante el período de 1962 a 1970, la organización de los obreros del sector industrial urbano fue muy difícil, principalmente por la oposición fuerte de las empresas hacia el sindicalismo y a la ausencia de garantías legales para los obreros que intentaban formar un sindicato o plantear un conflicto laboral. Estos nuevos obreros provenían del sector campesinado, lo que dificultaba su organización. Además, las organizaciones sindicales se mostraron incapaces para organizar a este nuevo sector de la clase obrera (Rojas, 1978; Alvarenga, 2005).

El último editorial sobre la celebración del primero de mayo del período de estudio se publicó en 1975, donde se resalta que algunos sindicatos decidieron no participar en el desfile de ese año, debido a que aducían que el desfile había perdido todo significado, que los trabajadores no tenían interés en este y que se repetía una serie de consignas sin un sustento real. Ante esto, La República recomienda que los males del país había que enfrentarlos no con desfiles sino con el estudio, la investigación, el desprendimiento personal, la disciplina, el coraje moral y el espíritu de trabajo. Sino existían estos mecanismos, todo sería evasión. Asimismo, señala que los trabajadores organizados debían de dedicarse a analizar los problemas económicos, sociales y morales del país a fondo $y$ definirse públicamente en relación con ellos en forma independiente, sin sometimiento a grupos de presión o a cálculos políticos o ideológicos (Los desfiles del $1^{\circ}$ de mayo, jueves 1 de mayo de 1975). Esta visión crítica es compartida por Marielos Aguilar cuando refiere las insuficiencias en el movimiento sindicalista, tales como, la inercia que no les permitió adaptarse a las nuevas condiciones posteriores al conflicto de 1948, la discordia sectaria y las prácticas antidemocráticas (Aguilar, 1989).

\section{CONCLUSIONES}

El estudio de los discursos periodísticos emitidos por la iglesia católica y La República con respecto a la celebración del primero de mayo entre 1956 y 1980, revelan la influencia político-mediática que estos periódicos ejercieron sobre los costarricenses durante la segunda mitad del siglo xx. La iglesia a través del Eco Católico expuso una posición moral-conservadora que invisibilizó la explotación del trabajador nacional. También recuerda que el primero de mayo se creó para festejar la rendición de William Walker, y que el social cristianismo era la mejor solución al conflicto de clases. Aparte de crear una celebración paralela a la que organizaban los sindicatos para mantener su presencia entre los sectores trabajadores nacionales, hace una crítica frontal a la institucionalidad, a la dominación política existente en el país y a lastres culturales como el paternalismo $y$ la vagancia. Todo esto ocurrió en un contexto histórico en el que la jerarquía de la iglesia católica conformó una relación simbiótica con el Estado, en la cual estaba interesada en mantener su influencia socio-política.

Sobre los discursos de La República, se tiene que estos giraron alrededor de un furibundo anticomunismo y las condiciones económicas adversas que enfrentaban los campesinos. Proponía abrir consultorios jurídicos gratuitos para el acceso y el beneficio del trabajador, recordaba que en un primer de mayo fue expulsado el filibustero William Walker y la necesidad de mantener la paz social. Por último, critica la conformación sindical de los años de estudio al enfatizar que los problemas del país había que enfrentarlos no con desfiles sino con el estudio, la investigación, el desprendimiento personal, la disciplina, el coraje moral y el espíritu de trabajo. Tanto el Eco Católico como La República demostraron el interés de que el primero de mayo se dejara de celebrar como el día del trabajo, ante lo que proponen devolverle su sentido patriótico de remembranza de la fecha histórica en que el filibustero William Walker se rindió frente a las tropas centroamericanas. Es notorio el interés de deslegitimar el primero de mayo como celebración del movimiento trabajador nacional. 


\section{REFERENCIAS}

1 de mayo. (Domingo 1 de mayo de 1966). La República. Año xvi. Nro.4701.

1 de mayo con trabajadores sin representación. (Domingo 30 de abril de 1972). Eco Católico. Año XL. Nro.17 (2124).

Aguilar, M. (1989). Clase trabajadora y organización sindical en Costa Rica 19431971. ICES-Porvenir-FLACSO.

Alvarenga, P. (2005). De vecinos a ciudadanos: movimientos comunales y luchas cívicas en la historia contemporánea de Costa Rica. Editorial de la Universidad de Costa Rica y Editorial de la Universidad Nacional.

Backer, J. (1975). La iglesia y el sindicalismo en Costa Rica. Segunda edición. Editorial Costa Rica.

Barrientos, J. (2019). Los amigos de Lucifer: la ideología anti comunista en Costa Rica. Editorial Arlekín.

Benavides, M. (2005). Relación entre Estado e Iglesia en Costa Rica a través de su historia. Revista de Historia de América, 136, 103-128.

Benedictino. (Domingo 28 de abril de 1957). Ennoblecer el trabajo. Eco Católico. Año xxvi. Nro.17 (1351).

Campos, D. (2000). Relaciones Iglesia-Estado en Costa Rica: un estudiohistórico-jurídico. Editorial Guayacán.

Campos, J. (Domingo 30 de abril de 1972). Los ticos en su salsa. Eco Católico. Año XL. Nro.17 (2124).

Chomsky, N. y Herman, E. (2000). Los guardianes de la libertad. Editorial Crítica.

Concentración católica del trabajo. (Domingo 30 de abril de 1961). Eco Católico. Año XxxI. Nro.18 (1557).

Día del trabajo. (Sábado 1 de mayo de 1965). La República. Año XIII. Nro.4079.

El día del trabajo. (Domingo 22 de abril de 1956). Eco Católico. Año xxvi. Nro.17 (1299).

El día del trabajo. (Jueves 1 de mayo de 1969). La República. Año xviII. Nro.5749.

El primero de mayo. (Domingo 4 de mayo de 1980). Eco Católico. Año XlviII. Nro.2551.
Fue borroso el día del trabajo. (Domingo 6 de mayo de 1979). Eco Católico. Año XLVII. Nro.2499.

Gamboa, M. (2013). El anticomunismo en Costa Rica y su uso como herramienta política antes y después de la guerra civil de 1948. Anuario de Estudios Centroamericanos, (39), 143-165. https:// revistas.ucr.ac.cr/index.php/anuario/ article/view/11798/11120

Guerra, A. (Domingo 7 de mayo de 1961). ¡A trabajar todo el mundo! Eco Católico. Año Xxxi. Nro.19 (1558).

Herrera, R. (2015). Lecciones urgentes: Las luchas de las clases trabajadoras en el siglo xx. Paquidermo, s.p. https://revistapaquidermo.com/archives/11794

Los camaradas atacan. (Domingo 9 de mayo de 1965). Eco Católico. Año xxxıv. Nro.19 (1765).

Los desfiles del $1^{\circ}$ de mayo. (Jueves 1 de mayo de 1975). La República. Año xxv. Nro.7906.

Los trabajadores queremos un diálogo. (Domingo 7 de mayo de 1967). Eco Católico. Año xxxv. Nro.19.

Manifiesto del $1^{\circ}$ de mayo de ORIT. (Miércoles 1 de mayo de 1963). La República. Año XII. No.2475.

Marín, J. J. y Torres, M. (2015). Musa obrera: historia, balances y desafíos de la clase trabajadora en el centenario del 1 de mayo en Costa Rica, 1913-2013. CIHAC.

Maroto, A. (2013). La confesionalidad del Estado costarricense: un proceso en constante renovación. Reflexiones, 92, 189-198.

Molina, I. y Palmer, S. (2017). Historia de Costa Rica. Tercera edición. Editorial de la Universidad de Costa Rica.

Molina, I. (2018). El financiamiento educativo público en Costa Rica a largo plazo (1860-2016). Historia y memoria, (16), 165-198. https://www.researchgate.net/ publication/323247630_El_financiamiento_educativo_publico_en_Costa_ Rica_a_largo_plazo_1860-2016

Montero, M. D. (1989). El discurso periodístico político en la creación de estructuras públicas de significatividades. Anàlisi, 
(12), 93-100. https://ddd.uab.cat/pub/anal isi/02112175n12/02112175n12p93.pdf

Muñoz, M. (2008-2009). Democracia y Guerra Fría en Costa Rica: el anticomunismo en las campañas electorales. https://revistas.ucr.ac.cr/index.php/dialogos/article/ view/6155/5859

Oliva, M. (1985). Artesanos y obreros costarricenses (1880-1914). Editorial Costa Rica.

Opazo, A. (1987). Costa Rica: La Iglesia Católica y el orden social. Departamento Ecuménico de Investigaciones.

Otro primero de mayo. (Martes 1 de mayo de 1973). La República. Año XxII. Nro.7194.

Picado, M. (1990). La iglesia costarricense entre el pueblo y el Estado: de 1949 a nuestros días. Segunda edición. Ediciones Guayacán.
Primero de mayo. (Lunes 1 de mayo de 1967). La República. Año XVI. Nro.5027.

Rojas, M. (1978). El desarrollo del movimiento obrero en Costa Rica; un intento de periodización. Revista de Ciencias Sociales, 15-16, 13-31.

Urbina, C. (2015). Gesta heroica, ocultamiento histórico e identidad de clase. La prensa costarricense y el 1 de mayo (18581913). Revista de Ciencias Sociales, 148 , 101-107.

Fecha de ingreso: 26/07/2019 Fecha de aprobación: 16/06/2020 